\title{
ПЕРСОНАЛИЗАЦИЯ ТРАЕКТОРИИ ПРОФЕССИОНАЛЬНОГО РАЗВИТИЯ РАБОТНИКОВ В УСЛОВИЯХ ИНДУСТРИИ 4.0
}

\author{
О. В. Будзинская \\ Российский государственный университет нефти и газа \\ (национальный исследовательский университет) имени И. М. Губкина
}

Поступила в редакцию 15 января 2020 г.

\begin{abstract}
Аннотация: статья посвящеена поиску решения по удовлетворению потребности в квалифицированных кадрах с новыми компетенциями в высокотехнологичных отраслях. Инструменты Индустрии 4.0 видоизменяют бизнес-процессы в организации и создают предпосылки к постоянному обновлению компетенций персонала. Традиционная система подготовки кадров, свойственная эпохе индустриализации, не способна удовлетворить спрос на трудовые ресурсы с качественно иными характеристиками на рынке труда. Следовательно, решение обозначенного вопроса перекладывается на работодателей и решение может быть найдено на уровне корпоративных университетов. Для удовлетворения потребности в квалифицированных кадрах с новыми компетенциями в высокотехнологичных отраслях автор предлагает кадровую технологию по выделению дефицитных компетенций в портфеле компетенций работника и построению персонализированной траектории профессионального развития.
\end{abstract}

Ключевые слова: кадровая политика, профессиональное развитие, профессиональные стандарты, компетенции.

\begin{abstract}
Article is devoted to the search for personnel technology to meet the need for qualified personnel with new competencies in high-tech industries. Industry 4.0 tools change business processes in an organization and create prerequisites for continuous updating of competencies. The conservative education system, which is typical of the era of industrialization and involves mass training, is not able to meet the demand for labor resources with qualitatively different characteristics. Therefore, the solution of this question is possible at the level of corporate universities. In the article, the author offers a personnel technology for the allocation of scarce competencies in the portfolio of employee competencies and the construction of a personalized trajectory of professional development.
\end{abstract}

Key words: personnel policy, professional development, professional standards, competence.

Фундаментальные изменения в парадигме экономики, бизнеса и социума, выражающиеся в «экспоненциальных темпах развития, широте и глубине применения цифровых технологий, системном воздействии (преобразовании) на все системы по всем странам, компаниям, отраслям и обществу в целом» поставили вопрос о поиске решений по быстрой и безболезненной трансформации рынка труда. Инициация технологической трансформации в сфере промышленности усилило интеграцию «киберфизических систем» или CPS в заводские процессы, которая приобрела глобальный характер. Инструменты Индустрии 4.0 видоизменили бизнес-процессы, сформировав потребность в новых компетенциях персонала. Массовое изменение качественных характеристик трудовых

(C) Будзинская О. В., 2020 ресурсов коснулось в первую очередь высокотехнологичных отраслей.

Мировое развитие нефтегазовой отрасли позволяет отнести ее к высокотехнологичному, наукоемкому сектору экономики на уровне атомного комплекса, ракетно-космической промышленности, высокотехнологичному производству химической отрасли и т. д. В настоящее время в нефтегазовой отрасли в основном производстве и сервисном обслуживании широко применяются технологические процессы, относящиеся к высокотехнологическому сектору. К высокотехнологичным производствам в нефтегазовом секторе можно отнести:

- современные геоинформационные технологии, космическое зондирование и мониторинг, трехмерную (3d) и четырехмерную сейсморазведку (4d);

- трехмерное моделирование залежей и гидродинамических процессов при разработке место- 
рождений с учетом временного фактора и объемной визуализации;

- технологии сооружения скважин с протяженными горизонтальными участками;

- проектирование и образование ледостойких платформ с целью бурения на арктическом шельфе;

- технологическую корпоративную связь (с применением спутниковой связи и систем JPS) и системы диспетчерского управления и автоматизации технологических процессов на базе микропроцессорной техники в добыче, транспорте и переработке нефти и газа;

- интегрированные системы управления в реальном времени;

- создание высокопроизводственных и экономичных газотурбинных аппаратов с целью перекачки газа и обеспечения электроэнергией [1].

Стремительно усложняющиеся техника и технологии, применяемые для поиска, добычи, транспортировки и переработки углеводородного сырья, обусловливают необходимость развития систем подготовки кадров, способных к быстрому освоению инновационных для отрасли, технических решений. Анализ программ инновационного развития ведущих компаний отрасли ПАО «Газпром», ПАО «Газпром-нефть», ПАО «Лукойл», ПАО «НК "Роснефть"» свидетельствует о важности кадровой политики, особенно в области профессионального развития персонала, в устойчивом развитии компаний [2-5].

Каскадирование уровней принятия решений по определению потребности в кадрах с новыми компетенциями представлено на рис. 1. Система технологического развития компаний ТЭК направлена на преодоление технологических вызовов, т. е. техно- логических проблем, которые препятствуют достижению стратегических целей. Данная проблема может быть решена с помощью внедрения новых технологий в рамках инновационной деятельности. Как правило, компании заинтересованы в технологических решениях, которые подтверждены на промышленном уровне. Компании заинтересованы в покупке технологических решений, доведенных до промышленного уровня, в пакете с технологическими сервисами. Итак, каждому технологическому вызову составляется перечень технологических решений, т. е. технологии, введение которой позволит преодолеть технологический вызов. Внедрение нового технологического решения предполагает выделение новых профессиональных компетенций, которые необходимы персоналу для имплементации новых технологий в целях достижения стратегических целей инновационного развития. Вариативность технологических решений в условиях нового технологического уклада настолько велика, что не представляется возможным стандартизировать набор требуемых компетенций работника по направлениям подготовки.

Традиционно кадровое обеспечение предприятий нефтегазового комплекса осуществлялось путем подготовки инженеров по направлению «Нефтегазовое дело», которое включало три специальности: «Проектирование, сооружение и эксплуатация газонефтепроводов и газонефтехранилищ», «Разработка и эксплуатация нефтяных и газовых месторождений» и «Бурение нефтяных и газовых скважин». Приказом Министерства образования Российской Федерации от 2 марта 2000 г. № 686 был утвержден государственный образовательный стандарт, положивший начало подготовке бакалавров.

\begin{tabular}{|c|c|}
\hline \multicolumn{2}{|c|}{ Первый уровень } \\
\hline Бизнес-стратегия & Стратегические цели \\
\hline Стратегия инновационного развития & $\begin{array}{c}\text { Технологический вызов } \\
(1,2,3 \ldots \text {... n) }\end{array}$ \\
\hline Второй уровень \\
\hline Третий уровень \\
\hline Технологическое решение & Новые компетенции \\
\hline
\end{tabular}

Puc. 1. Иерархия принятия решений по определению потребности в кадрах с новыми компетенциями 
В советское время кадровая политика была целиком подчинена плановой экономике. Координирующую связь между промышленностью и учебными заведениями выполняло государство. В Госплане СССР определялись количественные и качественные характеристики требующихся специалистов в соответствии с народно-хозяйственными планами развития, а отраслевые министерства уже спускали разнарядку в вузы, утверждая соответствующие образовательные программы. После окончания вузов выпускники получали распределение и были обязаны отработать три года. Такой алгоритм взаимодействия образования и промышленности через государственное регулирование позволял решить полностью кадровые проблемы.

В настоящее время в рамках четырехуровневого профессионального образования выделены три уровня высшего образования (далее - ВО), представленные на рис. 2. В Закон «Об образовании в Российской Федерации» № 273-Ф3 от 29 декабря 2012 г. внесены изменения, согласно которым начальное профессиональное образование упразднено, а профессиональное образование включает среднее профессиональное образование (далее - СПО) и высшее профессиональное образование (далее - ВПО). Уровни ВО отличаются квалификацией выпускников - уровнем знаний, умений, навыков и компетенций, характеризующих подготовленность к выполнению определенного вида профессиональной деятельности [6].

До начала 1990-х гг. подготовку по направлению «Нефтегазовое дело» осуществляли не более 10 вузов. На сегодняшний день в РФ функционирует 36 вузов, готовящих специалистов для нефтегазовой отрасли, а также 73 вуза по смежной направленности либо имеющие нефтяные факультеты. Тем не менее обширная образовательная сеть по подготовке инженерных кадров недостаточно ориентирована на меняющиеся запросы реального сектора экономики. «Технологическая модернизация требует соответствующего кадрового обеспечения. Фактически отсутствует система прогнозирования потребности в кадрах того или иного профиля, не ведётся мониторинг кадровой ситуации в большинстве отраслей экономики и социальной сферы. Недостаточно развита целевая, контрактная форма подготовки специалистов» [7]. Система квалификаций, созданная в эпоху индустриализации в России, отличалась жесткой взаимосвязью между системой образования и промышленностью, что выражалось в четкой номенклатуре специальностей, формировании контрольных цифр по приему в вузы на бюджетные места согласно прогнозным потребностям отраслей народного хозяйства, взаимосвязи тарификации работ и уровня образования работников. Так, в стране использовались Единый тарифно-квалификационный справочник работ и профессий рабочих (ЕТКС) и Единый квалификационный справочник должностей руководителей, специалистов и других служащих (ЕКСД).

Вышеприведенные элементы построения системы профессиональной квалификации свидетельствуют о фундаментальности подхода, но отсутствие вариативности и мобильности элементов системы не позволило справиться с стремительным потоком новой информации, скоростью технологического прогресса и не позволило в должной мере удовлетворить потребности рынка труда. Консервативная модель образования оказалась в положении догоняющего игрока на рынке труда. Отсутствие синхронизации требований Федеральных государственных образовательных стандартов (ФГОС) современным потребностям высокотехно-

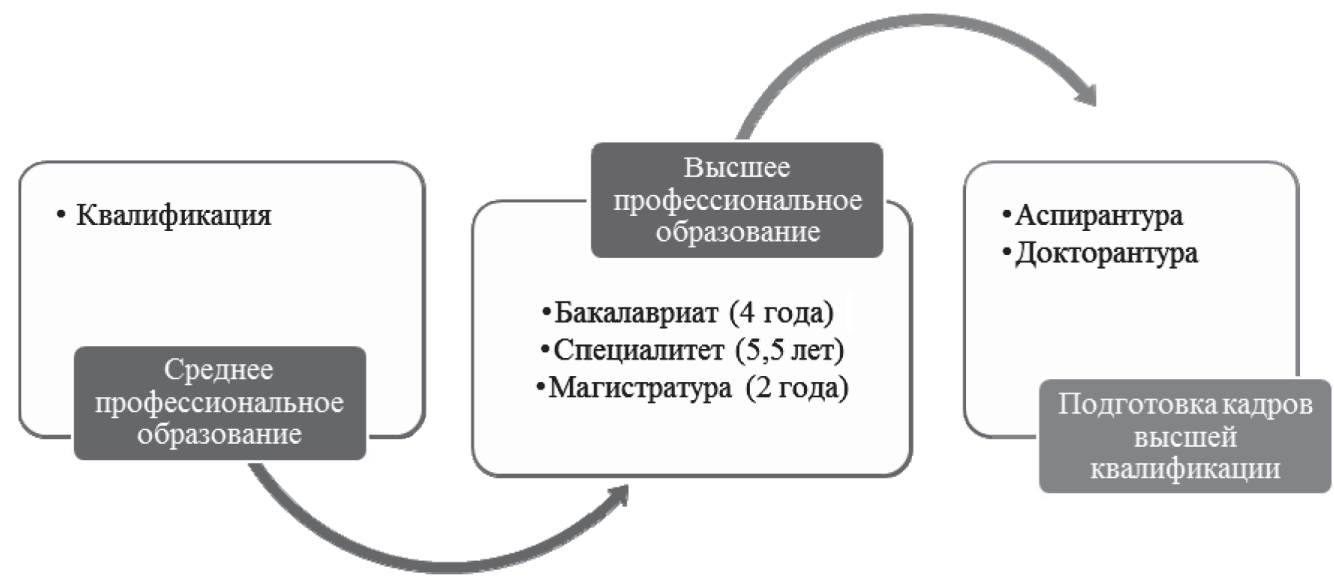

Puc. 2. Структура профессионального образования в России [6] 
логичного производства создает дисбаланс в квалификационном уровне выпускников высших учебных заведений к запросам работодателей.

Смена парадигмы социально-экономического развития общества всегда рождает вызовы, преодоление которых вызывает энтропийное сопротивление в обществе и, следовательно, на рынке труда [8]. Одной из основных причин, вызывающих отторжение к реформированию, является «институциональная ловушка» [9], когда сформированные старым режимом институты не способны поддерживать и развивать новые формы деятельности.

Кроме этого, несистемные решения, принятие которых является попыткой раскрутить сложившийся десятилетиями клубок проблем, просто не в состоянии выстроить систему институтов для кадрового обеспечения в цифровой экономике. По мнению экспертного сообщества, отсутствие системы институтов кадрового обеспечения является основным барьером (31 \% экспертов) для внедрения новых производственных технологий в России, отсутствие которого выражается в следующих чертах:

- низкая квалификация управленческого персонала, низкие «цифровые» компетенции топ-менеджеров;

- низкая квалификация инженерного персонала;

- малые зарплаты инженеров и научных работников [10].

Другими значимыми причинами дефицита высококвалифицированных нефтегазовых кадров являются недостаточно эффективное взаимодействие высших учебных заведений и других учебных заведений с успешно работающими научными и производственными организациями и компаниями; недостаток образовательных программ, отвечающих современным требованиям; несоответствие номенклатуры специальностей подготавливаемых специалистов реальным потребностям отрасли; отсутствие системы повышения квалификации кадров с учетом потребностей инновационного развития отрасли; отсутствие современных механизмов и инструментов управления кадровым обеспечением отрасли, способных эффективно прогнозировать и удовлетворять спрос на специалистов нефтяного профиля в условиях современного рынка труда. Данную точку зрения разделяют работодатели нефтегазовой отрасли, констатирующие дефицит кадров. Речь, безусловно, идет о качественном дефиците.

Сложившийся диссонанс системы профессиональной подготовки и требований рынка труда подвиг работодателей крупных холдингов искать решения по кадровому обеспечению компаний. В настоящее время стратегии управления персоналом крупных российских государственных и частных нефтяных компаний свидетельствуют об инновационном векторе развития человеческих ресурсов, техники и технологии на долгосрочную перспективу. Обеспечение квалификации персонала требованиям современных технологий заставило переосмыслить значение стратегии управления профессиональным развитием персонала в кадровой политике и положило начало стратегии развития человеческих ресурсов на основе непрерывного фирменного профессионального обучения.

Процесс разработки стратегии управления профессиональным развитием персонала в высокотехнологичных организациях, представленный на рис. 3, включает четыре этапа.

1. На первом этапе формулируется общая стратегия развития организации в долгосрочной перспективе, которая предполагает рост стратегического потенциала организации в инновационном и технико-технологическом развитии. Стратегия развития персонала полностью подчинена стратегии развития организации. Смена стратегических ориентиров организации влечет за собой изменение стратегии развития персонала.

2. На втором этапе на основе выбранной стратегии развития организации определяются количественные и качественные потребности в квалифицированных кадрах. С учетом стратегии развития выявляются компетенции, владение которыми персоналом необходимо для реализации поставленных бизнес-целей. Далее проводятся анализ кадровой структуры организации и оценка профессиональных компетенций. После чего путем сопоставления имеющихся кадровых ресурсов и желаемых разрабатывается стратегия развития персонала.

3. Стратегия развития персонала подразумевает разработку кадровых технологий профессионального развития персонала при соблюдении бюджета организации на обучение и профессиональное развитие персонала.

4. Внедрение кадровых технологий по профессиональному развитию предполагает регулярный контроль реализации принятой стратегии. Контроль качества обучения осуществляется через прирост эффективности труда работника. Проектирование модели управления знаниями организации способствует трансляции знаний в среду деятельности и способствует росту потенциала организации в инновационном развитии в долгосрочной перспективе. 


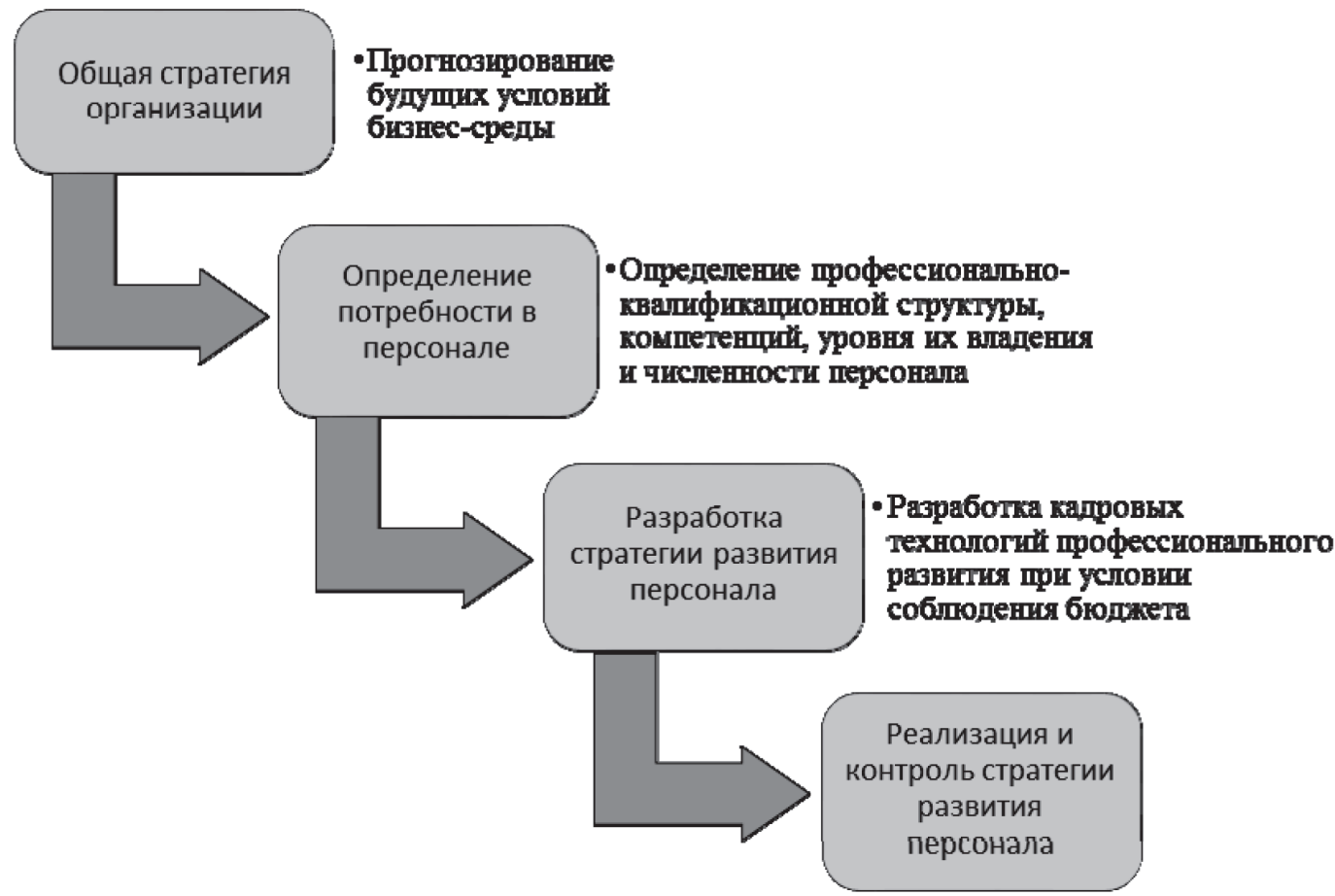

Рuc. 3. Процесс разработки стратегии управления профессиональным развитием персонала в высокотехнологичных организациях [составлено автором]

Таким образом, в крупных компаниях стратегия управления профессиональным развитием представляет собой систему взаимосвязанных действий, элементами которой являются выработка стратегии развития компании, прогнозирование и определение потребности в кадрах той или иной квалификации и компетентности, соотношение плана высвобождения должностей с планом подготовки кадрового резерва, адаптация, разработка планов развития персонала, управление карьерой, оценка персонала и т. д. Все вышеперечисленные функции структурных подразделений по управлению персоналом на протяжении долгого времени являлись важным элементом управления циклом профессиональной жизни человека от профессионального становления до приращения знаний и достижения мастерства в профессии. После имплементации инструментов Индустрии 4.0 цикл профессиональной жизни в рамках трудовой карьеры ускорился и стал более профессионалоемким, что на практике проявляется набором эксклюзивных компетенций работника.

Профессиональное развитие персонала в данных условиях обеспечивают корпоративные университеты через непрерывное фирменное профессиональное обучение персонала на каждой ступени карьерного роста. Компании ПАО «НК "Рос- нефть"», ПАО «Татнефть», ПАО «Газпром», ПАО «Газпром нефть», ПАО «Лукойл» и ряд других реализуют стратегические программы развития человеческих ресурсов на базе собственных учебных заведений с целью формирования компетенций, необходимых для эффективной работы в тактической и стратегической перспективе.

Корпоративный институт играет важную адаптационную роль для новых сотрудников к специфике компании, к корпоративной культуре. А для действующего персонала компании корпоративный институт является эффективным инструментом обеспечения его профессионального развития (рис. 4). Создание корпоративных университетов требует значительных вложений на долгосрочной основе: создание и поддержание материально-технической базы, организация полигонов для прохождения практических занятий, формирование высокопрофессионального преподавательского состава и т. д. Несмотря на внушительные затраты, западными коллегами доказано, что 1 доллар, инвестированный в обучение персонала, дает более 8 долларов отдачи.

В условиях цифровизации важно научиться выделять ядро профессиональных и личностных компетенций, переводить текущие проблемы в задачи, а задачи - в архитектуру решений. Ведь зада- 


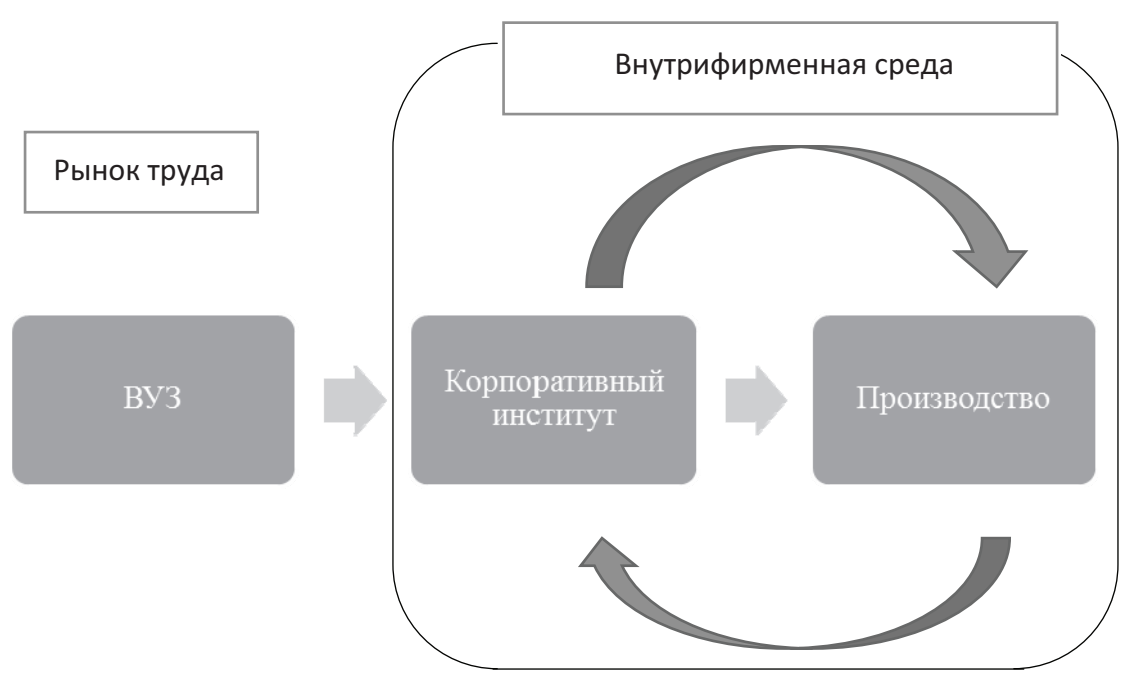

Puc. 4. Место корпоративного института в обучении персонала

ча принятия решений изменилась от просто выполнить до выполнить максимально эффективно. По мнению немецкого ученого H. Drumm, в этих условиях организация самостоятельно формирует потенциал способностей. Ученый представил развитие как «институциональную стабилизацию обучения». Развитие, по его мнению, может быть индивидуальным или организационным требованием [11].

На рис. 5 представлена методология каскадирования кадровой политики через рефлексию модели компетенций на индивидуальную профессиональную траекторию развития.

На стратегическом уровне разрабатываются принципы кадровой политики, на основе которых формируется корпоративная модель компетенций. Далее на тактическом уровне с учетом требований профессиональных стандартов составляется про- филь компетенций должностей. На операционном уровне, отображающем индивидуальный трудовой потенциал работника, путем наложения профиля компетенций должности и требований к квалификации, закрепленных в Профессиональном стандарте, на индивидуальный портфель компетенций работника можно выделить дефицитные компетенции, рекомендованные для дальнейшего профессионального развития согласно персонализированной траектории профессионального развития.

Таким образом, для достижения стратегических целей инновационной политики высокотехнологичных компаний ТЭК приоритетом становится выработка кадровой технологии персонализации профессионального развития персонала для удовлетворения потребности в кадрах с новыми компетенциями.

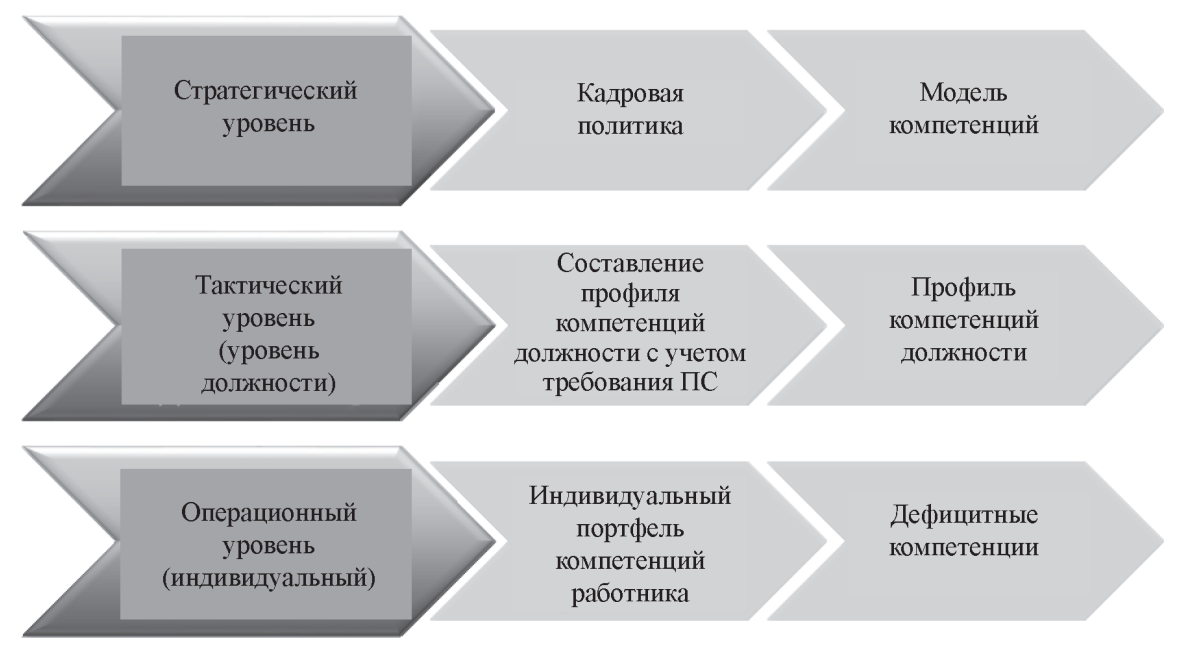

Рuc. 5. Кадровая технология персонализации профессионального развития персонала [предложено автором] 


\section{ЛИТЕРАТУРА}

1. Информаторий. Газпром. - URL: www.gazprominfo. ru/articles/prospecting/

2. Годовой отчет ПАО «Лукойл». Море возможностей. 2016. - URL: http://www.lukoil.ru/FileSystem/ PressCenter/121348.pdf

3. Годовой отчет ПАО «НК «Роснефть». Устойчивый рост. 2017. - URL: https://www.rosneft.ru/docs/report/2017/ download/full-reports/ar_ru_annual-report pages.pdf

4. Паспорт Программы инновационного развития ПАО «Газпром» до 2025 года. - URL: https:/www.gazprom.ru/f/ posts/97/653302/prir-passport-2018-2025.pdf

5. Паспорт Программы инновационного развития ПАО «Газпром нефть» до 2025 г. - URL: https://www. gazprom-neft.ru/files/documents/pir-pasport.pdf

6. Об образовании в Российской Федерации : федер. закон № 273-ФЗ от 29 декабря 2012 г. (с послед. изм. и доп.) - Доступ из справ.-правовой системы «КонсультантПлюс».

7. Выступление председателя Совета Федерации Валентины Матвиенко на парламентских слушаниях

Российский государственный университет нефти и газа (НИУ) имени И. М. Губкина

Будзинская О. В., кандидат экономических наук, доцент, докторант

E-mail:budzinskaya@bk.ru
«О государственной политике в сфере подготовки инженерно-технических кадров в РФ». - URL: http://www. unkniga.ru/news/1082-inzhenery.html

8. Будзинская О. В. Не допустить рост энтропии в формирующейся системе квалификаций / О. В. Будзинская, В. Г. Мартынов, В. С. Шейнбаум // Проблемы экономики и управления нефтегазовым комплексом. 2019. - № 6 (174). - С. 46-56.

9. Polterovich $V$. M. Institutional Traps: How to Get Out? / V. M. Polterovich // Economic Transformation and Evolutionary Theory of J. Shumpeter. The 5-th International Symposium on Evolutionary Economics (Puschino, September 25-27, 2003).

10. Барьеры в развитии цифровой экономики в субьектах РФ // Аналитический центр при Правительстве РФ. - URL: http://ac.gov.ru/files/publication/a/25838. pdf

11. Drumm H. J. Personalwirtschaft / H. J. Drumm. Berlin, 2002.

Gubkin Russian State University of Oil and Gas (National Research University)

Budzinskaya O. V., PhD., Associate Professor

E-mail:budzinskaya@bk.ru 